\title{
RNAi-mediated knockdown of Notch-1 leads to cell growth inhibition and enhanced chemosensitivity in human breast cancer
}

\author{
SHAOLEI ZANG ${ }^{1 *}$, FENG CHEN $^{1 *}$, JIANJIAN DAI $^{1}$, DONGMEI GUO $^{1}$, \\ WILLIAM TSE ${ }^{3}, \mathrm{XUN}^{2} \mathrm{QU}^{2}$, DAOXIN MA ${ }^{1}$ and CHUNYAN JI ${ }^{1}$ \\ ${ }^{1}$ Department of Hematology and ${ }^{2}$ Institute of Basic Medical Sciences, Qilu Hospital, Shandong University, Jinan, \\ Shandong Province 250012, P.R. China; ${ }^{3}$ Division of Medical Oncology, University of Colorado, Denver, CO, USA
}

Received December 2, 2009; Accepted January 15, 2010

DOI: $10.3892 /$ or_00000712

\begin{abstract}
Notch signaling plays a critical role in determining cell fate such as proliferation, differentiation, and apoptosis. Accumulating evidence indicates that aberrant Notch signaling has tumor-promoting function in breast cancer. We hypothesized that Notch signaling may be a potential therapeutic target for human breast cancer. To address this issue, we down-regulated the expression of the Notch-1 receptor by siRNA in human breast cancer cells. We found that the down-regulation of Notch-1 signaling caused cancer cell growth inhibition by apoptosis induction. The effect of the down-regulation of Notch-1 may be through the inactivation of NF-кB. In addition, the down-regulation of Notch-1 signaling increased chemosensitivity to doxorubicin and docetaxel. Our results suggested that Notch signaling may be a promising target for breast cancer treatment.
\end{abstract}

\section{Introduction}

Breast cancer is one of the leading causes of cancer-related death in women. The lifetime risk of developing breast cancer is about one in eight for women around the world. For example, about 182,000 new cases are diagnosed with breast cancer and 43,300 die in America each year. Although the survival of the breast cancer patients has improved with the chemotherapy, radiation therapy as well as hormone therapy, the outcome still remains poor. Therefore, the development of novel therapy strategies and discovery of more effective therapeutic targets are required and will greatly contribute to the treatment of breast cancer.

Correspondence to: Dr Chunyan Ji, Department of Hematology, Qilu Hospital, Shandong University, 107 West Wenhua Road, Jinan, Shandong Province 250012, P.R. China

E-mail: jichunyan@sdu.edu.cn

*Contibuted equally

Key words: Notch signaling, breast cancer, RNA interference; proliferation, apoptosis, chemosensitivity
Notch signaling is a pathway highly conserved through evolution which regulates various physiological processes, including stem cell maintenance, differentiation, proliferation and apoptosis. In mammals, key components of the Notch pathway include four transmembrane receptors (Notch 1-4) and five ligands (D111, D113, Dll4 and Jag-1, -2) (1,2). Direct binding of a ligand from a signaling cell to a Notch receptor on the membrane of the receiving cell initiates two successive proteolytic cleavages by TACE (TNF- $\alpha$-converting enzyme) and the $\gamma$-secretase/presenilin complex, which ultimately results in the release of the intracellular domain (N-IC). N-IC then translocates into the nucleus and directly interacts with the DNA binding protein $\mathrm{CBF} 1 / \mathrm{Su}(\mathrm{H}) / \mathrm{Lag} 1$ (CSF) that activates the transcription of target genes including the hairy/enhancer-of-split (HES-1) (3).

Accumulating evidence strongly indicates that aberrant Notch signaling has a tumor promoting function in breast cancer $(4,5)$. A role for Notch signaling in human breast cancer has been suggested by the development of adenocarcinomas in the murine mammary gland following either pathway activation or the loss of Numb expression, a negative regulator of the Notch pathway $(6,7)$. It was recently reported that the Notch signaling pathway also contributes to drug resistance in cancer cells. Inhibition of Notch signaling prevented drug resistance and sensitized myeloma cells to chemotherapy (8). Among the Notch Pathways, Notch-1 and Myc (a well studied oncogene) expression are positively correlated by immunostaining in $38 \%$ of examined human breast carcinomas (9). Notch-1 cross-talk has also been reported with other major cell growth and apoptotic regulatory pathways through modulating the activity of the transcription factor, for example, nuclear factor- $\kappa \mathrm{B}(\mathrm{NF}-\kappa \mathrm{B})(10)$. The existing evidence led us to hypothesize that Notch signaling may be a potential therapeutic target for human breast cancer.

In our earlier studies, we have shown that Notch-1 is overexpressed and highly activated in both human breast cancer cell lines and specimens (11). Thus, we tested our hypothesis on whether down-regulation of Notch-1 gene expression by small interfering RNA (siRNA) could inhibit cell growth and induce apoptosis.

We also explored whether the effects of down-regulation of Notch-1 were associated with the inactivation of NF- $\mathrm{KB}$. In addition, we examined the effect of the down-regulation of Notch signaling on sensitizing breast cancer cells to chemo- 
therapeutics. The results show that down-regulation of Notch-1 could be a novel therapeutic strategy for the treatment of human breast cancer.

\section{Materials and methods}

Cell culture and experimental reagents. Human breast cancer cell lines MDA-MB-231 and MCF-7 were cultured in RPMI1640 (Hyclone, Logan, UT) supplemented with 10\% fetal bovine serum (Hyclone) and $1 \%$ penicillin and streptomycin in a $5 \% \mathrm{CO}_{2}$ atmosphere at $37^{\circ} \mathrm{C}$. Notch-1 siRNA/siRNA control and Lipofectamine ${ }^{\mathrm{TM}} 2000$ were purchased from Invitrogen (Carlsbad, CA). SYBR Green Real-time PCR Master Mix was purchased from Toyobo (Osaka, Japan). RevertAid $^{\mathrm{TM}}$ First Strand cDNA Synthesis kit was from MBI (Fermentas, Hanover, MD). Annexin V-FITC kit was obtained from Jingmei Biotech (Shenzhen, China). Propidium Iodide was from Sigma (St. Louis, MO). Nuclear extract kit was purchased from Active Motif (Carlsbad, CA) 3-(4,5-dimethylthiazol-2-yl)-2,5-diphenyltetrazolium bromide (MTT) was obtained from Amresco (Cleveland, OH). Daunorubicin (Pharmacia Italia, S.P.A) was dissolved in phosphate-buffered solution (PBS) to make a $100 \mu \mathrm{g} / \mathrm{ml}$ stock solution. Docetaxel (Aventis Pharmaceuticals, Bridgewater, NJ) was dissolved in ethanol to make a $4 \mu \mathrm{mol} / 1$ stock solution.

SiRNA transfection. MDA-MB-231 and MCF7 cells $\left(1.2 \times 10^{5}\right)$ were seeded in 6-well plates (or 4000 cells/well in 96-well plates). After incubation overnight, cells (30-50\% confluence) were treated according to the protocol of the manufacturer with $40 \mathrm{nM}$ siRNA (5'-UCGCAUUGACCAU UCAAACUGGUGG-3') or control siRNA (does not match any known mammalian genebank sequences) which had been precomplexed with Lipofectamine ${ }^{\mathrm{TM}}$ 2000. Seventy-two hours after siRNA transfection, cells were used for MTT, real-time PCR, Western blotting and other experiments.

Cell growth inhibition by MTT assay. MDA-MB-231 and MCF-7 cells were incubated overnight at a density of 4000 cells/well in 96-well plates, and subsequently transfected with Notch-1 siRNA or siRNA control. Seventy-two hours after tansfection, $20 \mu 1$ of MTT was added per well. After an additional $4 \mathrm{~h}$ incubation, the media was removed, and $200 \mu \mathrm{l}$ of DMSO was added per well, followed by $10 \mathrm{~min}$ thorough mixing, color development was measured on a microplate reader at $570 \mathrm{~nm}$.

For the chemotherapeutic sensitivity assay, $24 \mathrm{~h}$ after transfection, cells were exposed to various doses of docetaxel or doxorubicin for an additional $48 \mathrm{~h}$ and the MTT assay was performed as described above.

Real-time RT-PCR. Total RNA was isolated from transfected cells by TRIzol (Invitrogen) according to the manufacturer's protocol. cDNA was synthesized with RevertAid ${ }^{\text {TM }}$ First Strand cDNA Synthesis kit. PCR reactions were carried out in a total of $25 \mu 1$ reaction mixture $(2 \mu 1$ of cDNA, $12.5 \mu 1$ of 2X SYBR Green PCR Master Mix, $1.5 \mu 1$ of forward and reverse primers and $7.5 \mu \mathrm{l}$ of $\mathrm{H}_{2} \mathrm{O}$ ). The PCR procedures were the following: preheating at $95^{\circ} \mathrm{C}$ for $10 \mathrm{~min} ; 45$ cycles of $95^{\circ} \mathrm{C}$ for $10 \mathrm{sec}, 60^{\circ} \mathrm{C}$ for $40 \mathrm{sec}$. Data were analyzed with com-parative $\mathrm{Ct}$ method and normalized by actin expression in each sample. Primer sequences for B-actin, Notch-1, Hes1 are available on request.

Apoptosis assay. Seventy-two hours after transfection of Notch-1 siRNA or control siRNA, the transfected MDAMB-231 and MCF7 cells were trypsinized, collected and washed twice with cold PBS. Cells were labeled by Annexin V and followed by PI. Annexin V-PI were measured by FACS Calibur and analyzed with the Modfit software. For the chemotherapeutic drug assays, $24 \mathrm{~h}$ after transfection, cells were exposed to $1.5 \mathrm{nM}$ docetaxel or $75 \mathrm{ng} / \mathrm{ml}$ doxorubicin respectively for $48 \mathrm{~h}$, then cells were collected and analyzed as above.

Western blot analysis. Cells were incubated at $4^{\circ} \mathrm{C}$ for $20 \mathrm{~min}$ in lysis buffer [50 mmol/1 Tris (pH 7.5), $100 \mathrm{mmol} / \mathrm{l} \mathrm{NaCl}$, $1 \mathrm{mmol} / \mathrm{l}$ EDTA, $0.5 \% \mathrm{NP} 40,0.5 \%$ Triton X-100, $2.5 \mathrm{mmol} /$ 1 sodium orthovanadate, $10 \mathrm{Al} / \mathrm{ml}$ protease inhibitor cocktail, $1 \mathrm{mmol} / \mathrm{l}$ phenylmethylsulfonyl fluoride]. The protein concentration was determined with the Bio-Rad assay system (Hercules, CA). Total proteins were fractionated using SDSPAGE and transferred onto nitrocellulose membrane. The membranes were blocked with $5 \%$ non-fat dried milk in PBS buffer containing $0.1 \%$ Tween-20 and then incubated with appropriate primary antibodies. The primary polyclonal antibodies of activated Notch-1 and Hes1 (Abcam, Ltd., Cambridge, UK). Horseradish peroxidase-conjugated antirabbit or anti-mouse IgG was used as the secondary antibody, and the protein bands were detected using the enhanced chemiluminesence detection system (Amersham, Buckinghamshire, UK). The results shown are representative of three independent experiments.

Electrophoretic mobility shift assay for measuring $N F-\kappa B$ activity. Nuclear extracts from MDA-MB-231 and MCF7 cells were prepared according to the manufacturer's instructions using a nuclear extraction kit and quantified by the BCA method. The NF- $\mathrm{BB}$ probes were generated by annealing equimolar complementary oligonucleotides in TEN buffers at $95^{\circ} \mathrm{C}$ for $10 \mathrm{~min}$ and then slowly cooling down to room temperature. The double-stranded probes were labeled with digoxigenin (Roche, Germany) using terminal transferase (Roche). For EMSA, 32 fmol of labeled probes were incubated at $25^{\circ} \mathrm{C}$ for $20 \mathrm{~min}$ with $2 \mu \mathrm{g}$ of nuclear extracts in the presence of $1 \mu \mathrm{g}$ of poly (dI-dC), $0.1 \mu \mathrm{g}$ of poly L-lysine, $30 \mathrm{mmol} / 1 \mathrm{KCl}, 20 \mathrm{mmol} / \mathrm{l} \mathrm{HEPES}, 10 \mathrm{mmol} / 1\left(\mathrm{NH}_{4}\right)_{2} \mathrm{SO}_{4}$, $1 \mathrm{mmol} / 1 \mathrm{DTT}, 0.2 \% \mathrm{v} / \mathrm{v}$ Tween-20, $1 \mathrm{mmol} / 1$ EDTA. Competition experiments were performed using a similar EMSA conditions as described above, except that the protein extracts were incubated with the probe in the presence of 250 -fold molar excess of unlabeled double-stranded oligonucleotides as competitors. After the DNA-protein complexes were separated from the free probes by electrophoresis through a $5 \%$ non-denaturing polyacrylamide gel, the gel was transferred to a PVDF membrane and chemiluminescent detection was performed.

Densitometric and statistical analysis. The bidimensional optical densities of Notch-1 and $\beta$-actin proteins on the film 
a

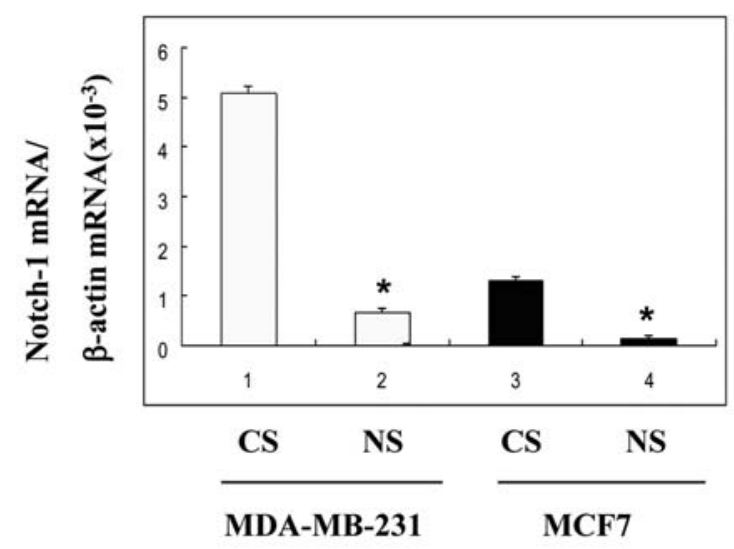

C

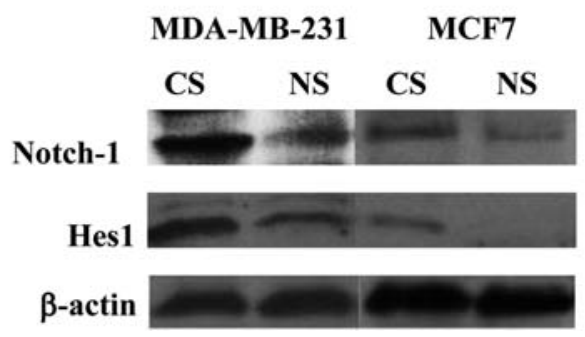

b

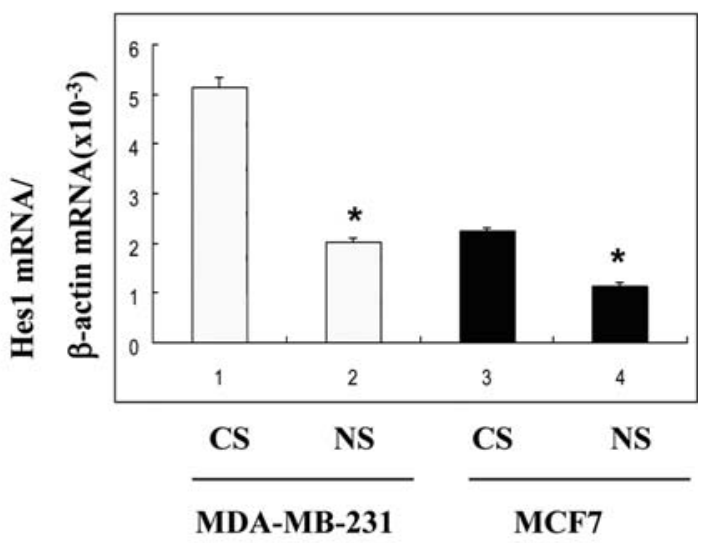

Figure 1. Down-regulation of Notch-1 and its target gene Hes1 by siRNA in human breast cancer cell lines MDA-MB-231 and MCF7. CS, control siRNA; NS, Notch-1 siRNA. (a) and (b), Notch-1 and Hes1 mRNA level was measured by real-time RT-PCR. (c), Notch-1 and Hes1 protein level was measured by Western blotting. The data are from three independent experiments, ${ }^{*} \mathrm{P}<0.05$.

were quantified and analyzed by Molecular Analyst software (Bio-Rad). The ratios of Notch-1 against $\beta$-actin were calculated. The cell growth inhibition by transfection or the combination of transfection and drug treatment was evaluated statistically by using Stat-Mate software (GraphPad Software, Inc., San Diego, CA). P $<0.05$ was considered statistically significant.

\section{Results}

Notch-1 siRNA effectively down-regulated the expression level of Notch-1 in human breast cancer cells. To definitely test the down-regulation effect of RNAi on Notch signaling pathway, two types of human breast cancer cell lines with high levels expression of Notch-1, MDA-MB-231 (estrogen receptor negative) and MCF-7 (estrogen receptor positive) were chosen in this study. We initially examined knockdown efficiency of different concentrations of siRNA on Notch-1 mRNA expression and chose the concentration of $40 \mathrm{nM}$ with the highest interfering efficiency for further analysis. After transfected with Notch-1 siRNA or control siRNA for $72 \mathrm{~h}$, the cell lines were collected to examine the expression of Notch-1 and Hes 1 at the mRNA and protein levels by real-time RT-PCR and Western blot analysis, respectively. As shown in Fig. 1a and $b$, Notch-1 and Hes1 mRNA were decreased by about 90\% in both MDA-MB-231 and MCF7 cells. Protein levels were also greatly reduced in Notch-1 siRNA-transfected cells compared with control siRNA-transfected cells (Fig. 1c). To exclude the possibility of RNAi off-target effects, we performed the experiments with different siRNAs and obtained similar results, indicating that the effects indeed resulted from Notch-1-RNAi interfere. On the basis of these results, we concluded that Notch-1 siRNA can effectively down-regulate the expression level of Notch-1 in human breast cancer cells.

SiRNA-mediated down-regulation of Notch-1 inhibits cell growth and induces apoptosis in human breast cancer. To investigate whether Notch-1 could be an effective therapeutic target for breast cancer, the effect of Notch-1 siRNA on cell growth was evaluated by MTT assay. We found that the downregulation of Notch-1 expression caused an $\sim 40 \%$ reduction of cell growth in both breast cancer cell lines at 3 days after siRNA transfection (Fig. 2). To investigate whether the growth-inhibitory effects of Notch-1 RNAi were related to the induction of apoptosis, cells transfected after $72 \mathrm{~h}$ were stained with Annexin V-PI and analyzed by flow cytometry. Given the fact that late apoptosis contains necrosis cells, although total apoptosis rate changed apparently, only early apoptosis is taken into account in our study. Compared with 1.25 and $0.94 \%$ in control siRNA transfected cells, the early apoptosis rates were 5.64 and $2.88 \%$ in Notch-1 siRNA transfected MDA-MB-231 and MCF7 respectively (Fig. 3). These data suggested that the growth inhibition induced by Notch-1 siRNA was partially due to an increase in cell apoptosis.

Down-regulation of Notch-1 expression by siRNA reduces $N F-\kappa B D N A$-binding activity. Both Notch signaling and NF-кB pathway are involved in cell-fate determination and differen- 
MDA-MB-231

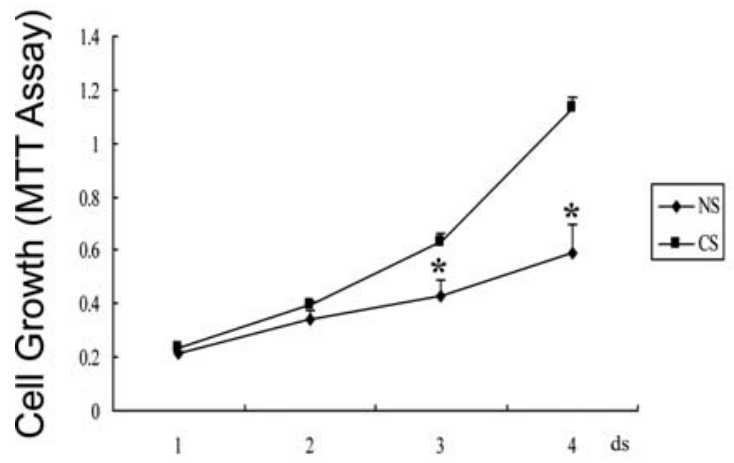

MCF7

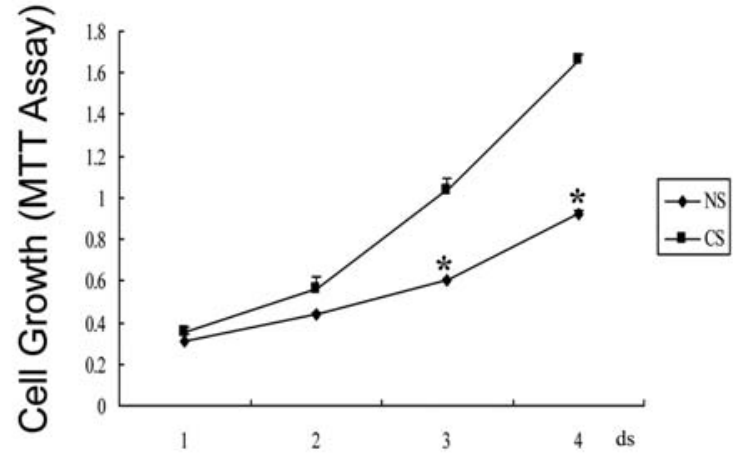

Figure 2. Effect of down-regulation of Notch-1 by siRNA on breast cancer cell growth. Cell growth inhibition tested by MTT assay in MDA-MB-231 and MCF7. ${ }^{*} \mathrm{P}<0.05,{ }^{* *} \mathrm{P}<0.01$. Data were from three independent experiments. ds, days after transfection.

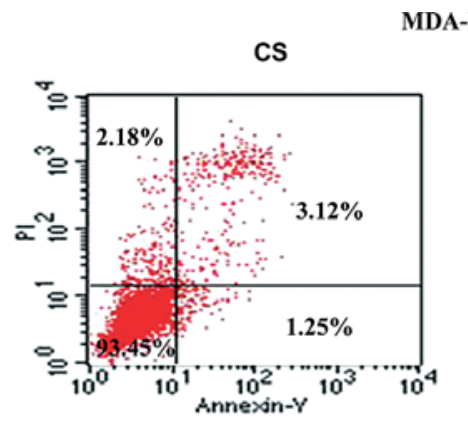

MDA-MB-231

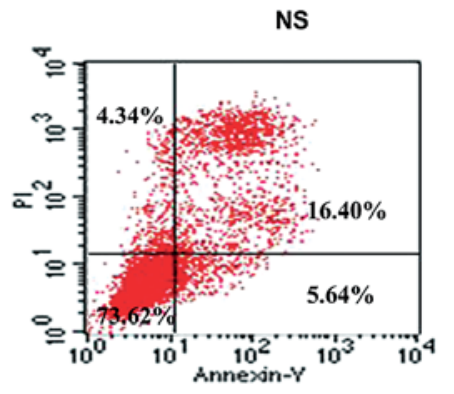

MCF7
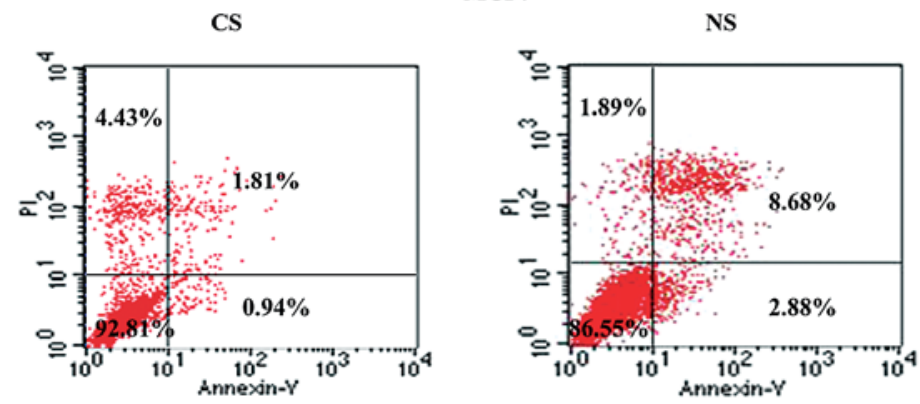

Figure 3. Effect of the down-regulation of Notch-1 on cell apoptosis. Transfected MDA-MB-231 and MCF7 cells were harvested and stained with Annexin V-PI. Apoptosis rates were analysised by flow cytometry. Down-regulation of Notch-1 increased the apoptosis rate of both MDA-MB-231 and MCF7 cells. We only took the early apoptosis rates into account because it is more representative. Each experiment was repeated twice to confirm the result.

tiation in different organisms and cell types. It was reported that there is cross-talk between these two pathways in human cervical and pancreatic cancer and that Notch signaling may be the upstream regulator $(10,12)$. We hypothesized that down-regulation of the downstream effects of Notch-1 could be related to the activity of the NF- $\mathrm{NB}$ pathway in human breast cancer. To address this hypothesis, we examined the NF-кB DNA-binding activity by EMSA. Down-regulation of Notch-1 significantly inhibited NF-кB DNA-binding activity compared with control cells in both MDA-MB-231 and MCF7 cells (Fig. 4). These results provide evidence that cross-talk also exists between Notch-1 and NF-кB in breast cancer.
Down-regulation of Notch-1 expression by siRNA increases chemosensitivity. Since Notch signaling pathway has been recently shown to contribute to drug resistance in cancer cells, we examined if the down-regulation of Notch-1 could sensitize breast cancer cells to frequently used chemotherapeutic drugs such as doxorubicin and docetaxel. We tested the effect of the combination of various doses of doxorubicin/docetaxel and Notch-1 siRNA on MDA-MB-231 cells. Compared to control siRNA transfected cells, downregulation of Notch-1 led to more cell death in MDA-MB-231 (data not shown). We chose $1.5 \mathrm{nM}$ doxorubicin and $75 \mathrm{ng} /$ $\mathrm{ml}$ docetaxel for further experiments.

The effect of down-regulation of Notch-1 combined with $1.5 \mathrm{nM}$ doxorubicin or $75 \mathrm{ng} / \mathrm{ml}$ docetaxel on the growth of 


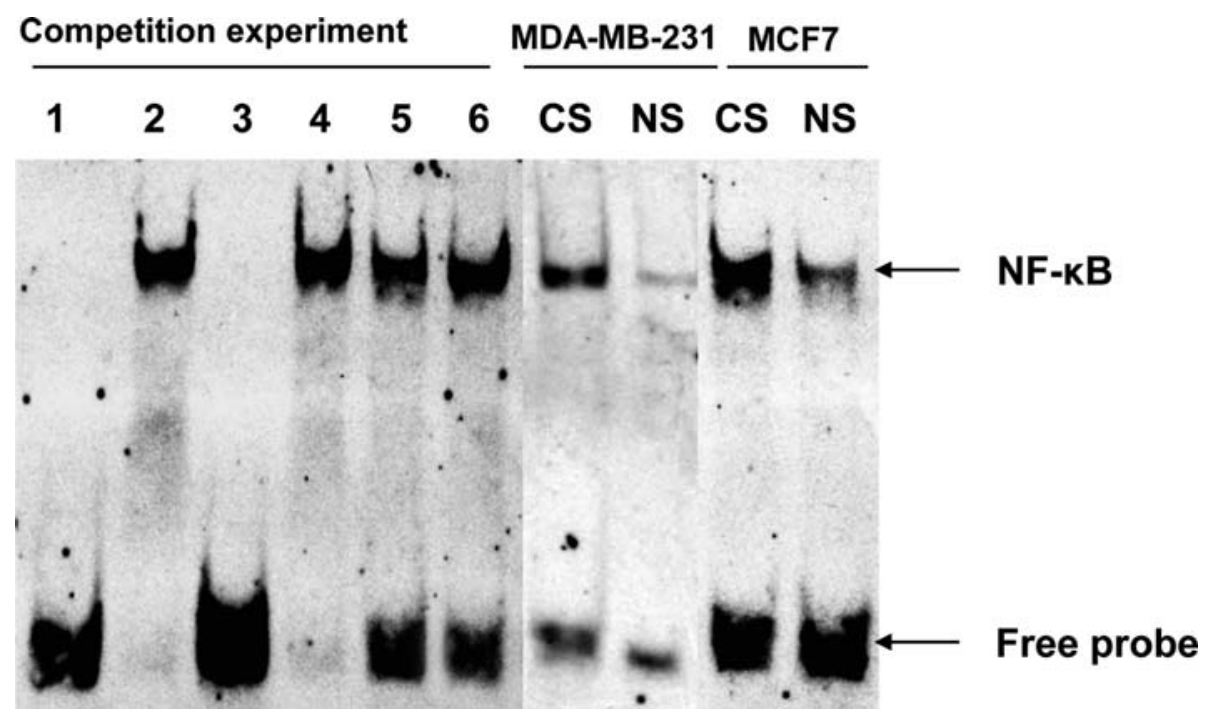

Figure 4. Effect of the down-regulation of Notch-1 on NF-кB DNA binding activity. Nuclear proteins from control siRNA and Notch-1 siRNA transfected

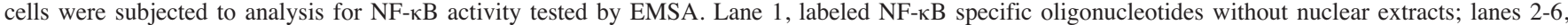
labeled NF-кB specific oligonucleotides with nuclear extracts plus 250 -fold excess amount of unlabeled NF- $\mathrm{B}$ specific oligonucleotides in lane 3 , unlabeled mutant NF-кB oligonucleotides in lane 4, unlabeled heterogenous sequence in lane 5 and unlabeled ARE in lane 6 . All the competitive assay confirmed the

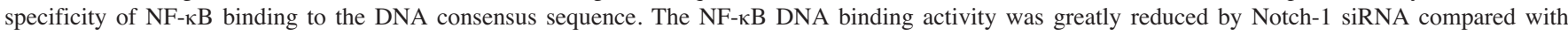
control in both MDA-MB-231 and MCF7 cells.

MDA-MB-231

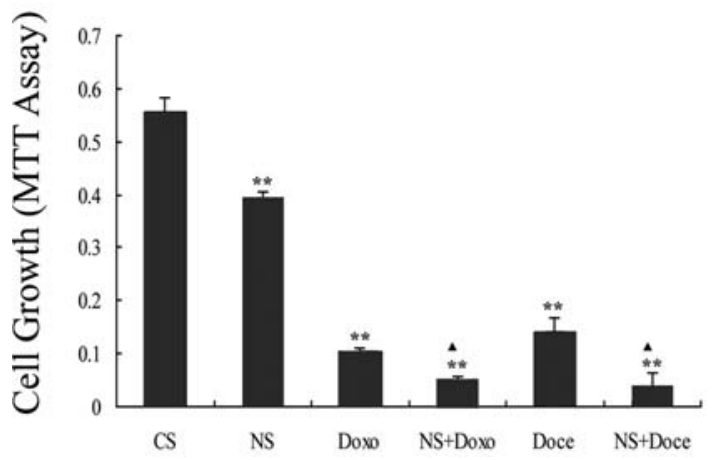

MCF7

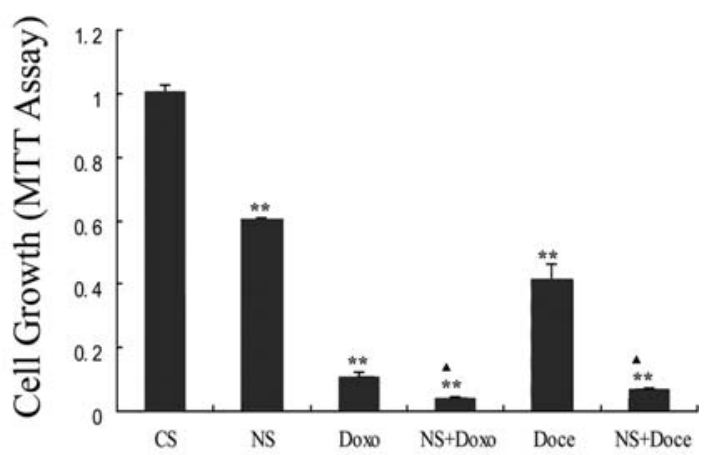

Figure 5. Inhibition of cancer cell growth tested by MTT assay. We analysed $75 \mu \mathrm{g} / \mathrm{ml}$ doxorubicin or $1.5 \mathrm{nM}$ docetaxel with combination with Notch-1 down-regulation in MDA-MB-231 and MCF7 cells. CS, control siRNA; NS, Notch-1 siRNA; Doxo, $75 \mu \mathrm{g} / \mathrm{ml}$ doxorubicin; NS+Doxo, Notch-1 siRNA and $75 \mu \mathrm{g} / \mathrm{ml}$ doxorubicin combination; Doce, $1.5 \mathrm{nM}$ docetaxel; NS+Doce, Notch-1 siRNA and $1.5 \mathrm{nM}$ docetaxel combination. ${ }^{* *} \mathrm{P}<0.01$, compare with control; $\Delta \mathrm{P}<0.05$ compare with mono-treatment; $\mathrm{n}=3$.

both cell lines is shown in Fig. 5. We found that the combination of Notch-1 down-regulation and docetaxel or doxorubicin led to a 50 or $70 \%$ enhancement in growth inhibition respectively as compared to single chemotherapeutic treatment in MDA-MB-231 cells. Similar results were found in MCF7 cells.

To further clarify the mechanism of enhanced growth inhibition of breast cancer cells by the combination of downregulation of Notch-1 and chemotherapeutic agents, we detected apoptosis rates induced by doxorubicin and docetaxel after the down-regulation of Notch-1. It was showed that the combination of Notch-1 down-regulation with doxorubicin increased the early apoptosis rate 4- and 2.5-fold in MDAMB-231 and MCF7 cells, respectively. Similarly, downregulation of Notch-1 combined with docetaxel increased the early apoptosis rate 5- and 6-fold in MDA-MB-231 and MCF7 cells, respectively. Taking together, the Notch-1 siRNA transfected MDA-MB-231 and MCF7 cells were significantly more sensitive to docetaxel and doxorubicininduced apoptosis (Fig. 6).

\section{Discussion}

Notch signaling plays important roles in maintaining the balance among cell proliferation, differentiation and apoptosis. The aberrant activation of Notch signaling has been reported in many human malignancies including human T-ALL, cervical cancer, and prostate cancer (12-14). Recently, Notch receptor expression levels have been found to be elevated in human breast cancer cell lines and breast cancer specimen 
MDA-MB-231

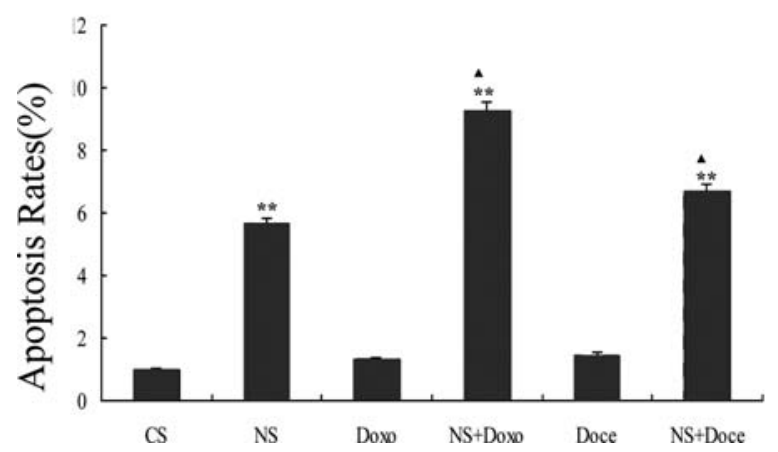

MCF7

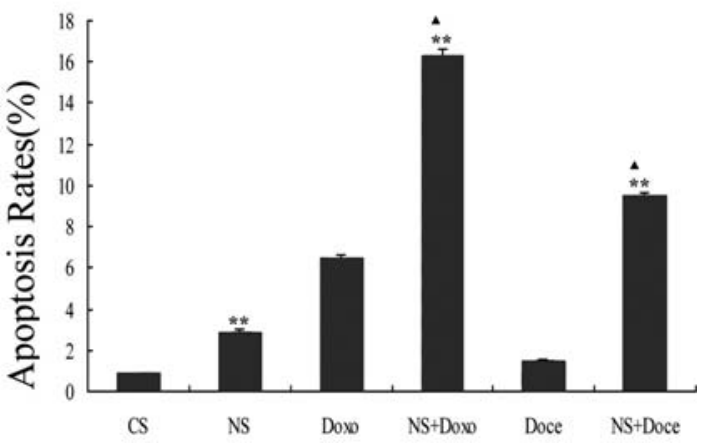

Figure 6. Induction of apoptosis in cancer cells tested by flow cytometry. CS, control siRNA; NS, Notch-1 siRNA; Doxo, $75 \mu$ g/ml doxorubicin; NS+Doxo, Notch-1 siRNA and $75 \mu \mathrm{g} / \mathrm{ml}$ doxorubicin combination; Doce, $1.5 \mathrm{nM}$ docetaxel; NS+Doce, Notch-1 siRNA and $1.5 \mathrm{nM}$ docetaxel combination. ${ }^{* *} \mathrm{P}<0.01$, compare with control; $\wedge \mathrm{P}<0.05$ compare with mono-treatment.

$(6,15)$. A study on human breast cancer showed that $50 \%$ of human breast tumors expressed reduced protein level of Numb, a negative regulator of Notch signaling (7). These findings highlight an oncogenic role for Notch signaling in human breast cancer.

In the present study, we tested whether Notch signaling could be a therapeutic target for breast cancer. We found that the down-regulation of Notch-1 inhibited the growth of human breast cancer cells by inducing apoptosis. The effect of the down-regulation of Notch-1 may be through the inactivation of NF-кB. In addition, the down-regulation of Notch-1 can sensitize human breast cancer cells to chemotherapeutics such as docetaxel and doxorubicin. Our results provided in vitro evidence that Notch-1 is a therapeutic target of human breast cancer and may be a promising target in combination with other chemotherapeutics.

It has been reported that the Notch gene suppresses apoptosis and promotes cell proliferation through a growth factor-mediated survival pathway (16). Down-regulation of Notch-1 was found to cause apoptosis in adult T-ALL and pancreatic cancer $(17,18)$. Yet there is discrepancy about the effect of down-regulation of Notch-1 on human breast cancer. Yamaguchi et al demonstrated that down-regulation of Notch-1 by RNA interference had little or no suppressive effect on the proliferation of either ERbB2-positive or ErbB2-negative cell line (19). However, in a recently published work, Notch-1 knockdown or $\gamma$-secretase inhibition was found to decrease cyclins A and B1, causing G2 arrest, and eventually cell death of breast cancer cells (20). In the present study, we again demonstrated that both MDA-MB-231 and MCF7 breast cancer cells have reduced growth and increased apoptosis after down-regulation of Notch-1. This is further evidence that Notch-1 is a potent therapeutic target for human breast cancer.

It was reported that $\mathrm{CD} 24^{-/ \mathrm{Low}} / \mathrm{CD} 44^{+}$cancer initiating cells, which were isolated from MDA-MB-231 and MCF7 breast cancer monolayer culture and propagated as mammospheres were more resistant to radiation than cells grown as monolayer cultures (21). Radiation increased the number of these cells through induction of Jagged-1 expression and subsequent activation of Notch-1. We found that siRNA transfected cells were more sensitive to chemotherapeutics such as docetaxel and doxorubicin. The previous and our current study suggested that Notch-1 activation was involved in radiation and chemotherapy resistance. This finding has an important implication for clinical significance because docetaxel and doxorubicin are frequently used in various cancers including breast cancer. To achieve greater inhibitory effects on cancer cells, the combination of two or more chemotherapeutic agents is commonly considered. Our results provide in vitro evidence that the down-regulation of Notch-1 in combination with other chemotherapeutics could be a novel strategy to achieve better treatment outcomes in human breast cancer.

$\mathrm{NF}-\kappa \mathrm{B}$ is another major cell growth and apoptosis regulatory pathway. $\mathrm{NF}-\kappa \mathrm{B}$ mediates survival signals that inhibit apoptosis and promote cancer cell growth. However, $\mathrm{NF}-\kappa \mathrm{B}$ is activated by both chemotherapeutics and radiation, in many cases this response may inhibit the ability of cancer therapies to induce cell death. There is known to be crosstalk between the NF-кB and Notch signaling pathways. In hemopoietic progenitor cells, NF-kB activity is regulated by Notch-1 via transcriptional control of NF-кB (22). It was also shown that, in Notch-1 induced T-cell leukemia, NF-кB was identified as one of the major mediators of Notch-1 induced transformation (23). We observed that the activity of NF-kB decreased with the down-regulation of Notch-1 signaling in MDA-MB-231 and MCF7 cells. The result suggests that the down-regulation of Notch-1 may be partly mediated by the $\mathrm{NF}-\kappa \mathrm{B}$ pathway. Future work exploring the connections between the Notch and NF-кB signaling pathways may elucidate more potential therapeutic targets.

\section{Acknowledgements}

The study was supported by National Nature Science Foundation of P.R. China (30471941), National Nature Science Foundation of P.R. China (30871088), Specialized Research Fund for the Doctoral Program of Higher Education (SRFDP) (20060422051), Bureau of Science and Technology 
of Shandong Province, P.R. China (2005GG4202018), Bureau of Science and Technology of Shandong Province, P.R. China (03BS025), International Cooperation Projects in Science and Technology of Shandong Province, P.R. China (200612). We also thank Dr David Wald (Department of Pathology, University Hospitals, Case Medical Center) for his critical reading of this manuscript.

\section{References}

1. Bigas A, Martin DI and Milner LA: Notch1 and Notch2 inhibit myeloid differentiation in response to different cytokines. Mol Cell Biol 18: 2324-2333, 1998.

2. Mumm JS and Kopan R: Notch signaling: from the outside in. Dev Biol 228: 151-165, 2000 .

3. Stockhausen MT, Sjölund J and Axelson H: Regulation of the Notch target gene Hes-1 by TGFalpha induced Ras/MAPK signaling in human neuroblastoma cells. Exp Cell Res 1: 218-228, 2005.

4. Stylianou S, Clarke RB and Brennan K: Aberrant activation of Notch signaling in human breast cancer. Cancer Res 66: $1517-1525,2006$.

5. Farnie G, Clarke RB, Spence K, Pinnock N, Brennan K, Anderson NG and Bundred NJ: Novel cell culture technique for primary ductal carcinoma in situ: role of Notch and epidermal growth factor receptor signaling pathways. J Natl Cancer Inst 99: 616-627, 2007

6. Imatani A and Callahan R: Identification of a novel NOTCH-4/ INT-3 RNA species encoding an activated gene product in certain human tumor cell lines. Oncogene 19: 223-231, 2000.

7. Pece S, Serresi M, Santolini E, Capra M, Hulleman E, Galimberti V, Zurrida S, Maisonneuve P, Viale G and Di Fiore PP: Loss of negative regulation by Numb over Notch is relevant to human breast carcinogenesis. J Cell Biol 167: 215-221, 2004.

8. Nefedova Y, Sullivan DM, Bolick SC, Dalton WS and Gabrilovich DI: Inhibition of Notch signaling induces apoptosis of myeloma cells and enhances sensitivity to chemotherapy. Blood 111: 2220-2229, 2008.

9. Efstratiadis A, Szabolcs M and Klinakis A: Notch, Myc and breast cancer. Cell Cycle 6: 418-429, 2007.

10. Yao J, Duan L, Fan M, Yuan J and Wu X: Notch1 induces cell cycle arrest and apoptosis in human cervical cancer cells: involvement of nuclear factor kappa B inhibition. Int J Gynecol Cancer 17: 502-510, 2007.

11. Zang S, Ji Ch, Qu X, Dong X, Ma D, Ye J, Ma R, Dai J and Guo D: A study on Notch signaling in human breast cancer. Neoplasma 54: 304-310, 2007.

12. Wang Z, Banerjee S, Li Y, Rahman KM, Zhang Y and Sarkar FH: Down-regulation of notch-1 inhibits invasion by inactivation of nuclear factor-kappaB, vascular endothelial growth factor, and matrix metalloproteinase- 9 in pancreatic cancer cells. Cancer Res 66: 2778-2784, 2006.
13. Weng AP, Ferrando AA, Lee W, Morris JP, Silverman LB, Sanchez-Irizarry C, Blacklow SC, Look AT and Aster JC: Activating mutations of NOTCH1 in human T cell acute lymphoblastic leukemia. Science 306: 269-271, 2004.

14. Shou J, Ross S, Koeppen H, De Sauvage FJ and Gao WQ: Dynamics of notch expression during murine prostate development and tumorigenesis. Cancer Res 61: 7291-7297, 2001.

15. Reedijk M, Odorcic S, Chang L, Zhang H, Miller N, McCready DR, Lockwood G and Egan SE: High-level coexpression of JAG1 and NOTCH1 is observed in human breast cancer and is associated with poor overall survival. Cancer Res 65: 8530-8537, 2005.

16. Haruki N, Kawaguchi KS, Eichenberger S, Massion PP, Olson S, Gonzalez A, Carbone DP and Dang TP: Dominant-negative Notch3 receptor inhibits mitogen-activated protein kinase pathway and the growth of human lung cancer. Cancer Res 65: 3555-3561, 2005 .

17. Wang Z, Zhang Y, Banerjee S, Li Y and Sarkar FH: Inhibition of nuclear factor $\mathrm{kb}$ activity by genistein is mediated via Notch-1 signaling in pancreatic cancer cells. Int J Cancer 118: 1930-1936, 2006.

18. Weng AP, Nam Y, Wolfe MS, Pear WS, Griffin JD, Blacklow SC and Aster JC: Growth suppression of pre-T acute lymphoblastic leukemia cells by inhibition of notch signaling. Mol Cell Biol 23: 655-664, 2003.

19. Yamaguchi N, Oyama T, Ito E, Satoh H, Azuma S, Hayashi M, Shimizu K, Honma R, Yanagisawa Y, Nishikawa A, Kawamura M, Imai J, Ohwada S, Tatsuta K, Inoue J, Semba K and Watanabe S: NOTCH3 signaling pathway plays crucial roles in the proliferation of ErbB2-negative human breast cancer cells. Cancer Res 68: 1881-1888, 2008.

20. Rizzo P, Miao H, D'Souza G, Osipo C, Yun J, Zhao H, Mascarenhas J, Wyatt D, Antico G, Hao L, Yao K, Rajan P, Hicks C, Siziopikou K, Selvaggi S, Bashir A, Bhandari D, Marchese A, Lendahl U, Qin JZ, Tonetti DA, Albain K, Nickoloff BJ and Miele L: Cross-talk between Notch and the estrogen receptor in breast cancer suggests novel therapeutic approaches. Cancer Res 68: 5226-5235, 2008.

21. Phillips TM, McBride WH and Pajonk F: The response of CD24 (-/low)/CD44+ breast cancer-initiating cells to radiation. J Natl Cancer Inst 98: 1777-1785, 2006.

22. Cheng P, Zlobin A, Volgina V, Gottipati S, Osborne B, Simel EJ, Miele L and Gabrilovich DI: Notch-1 regulates NF-kappaB activity in hemopoietic progenitor cells. J Immunol 167: 4458-4467, 2001.

23. Vilima T, Mascarenhas J, Palomero T, Mandal M, Buonamici S, Meng F, Thompson B, Spaulding C, Macaroun S, Alegre ML, Kee BL, Ferrando A, Miele L and Aifantis I: Targeting the NFkappaB signaling pathway in Notch1-induced T-cell leukemia. Nat Med 13: 70-77, 2007. 